\title{
Serum $\beta 2$-microglobulin: An independent risk factor for mortality in patients with acute respiratory distress syndrome caused by bacterial infection
}

\section{Liming Zhang ( $\square$ zhangliming@bjcyh.com )}

Beijing Institute of Respiratory Medicine and Beijing Chao-Yang Hospital, Capital Medical University $\mathrm{Na}$ Cui

Beijing Institute of Respiratory Medicine and Beijing Chao-Yang Hospital, Capital Medical University

\section{Xiaokai Feng}

Beijing Institute of Respiratory Medicine and Beijing Chao-Yang Hospital, Capital Medical University

Chunguo Jiang

Beijing Institute of Respiratory Medicine and Beijing Chao-Yang Hospital, Capital Medical University Jing Wang

Beijing Institute of Respiratory Medicine and Beijing Chao-Yang Hospital, Capital Medical University

\section{Research Article}

Keywords: acute respiratory distress syndrome, $\beta 2$-microglobulin, mortality, oxygenation

Posted Date: February 23rd, 2022

DOI: https://doi.org/10.21203/rs.3.rs-1354267/v1

License: (9) This work is licensed under a Creative Commons Attribution 4.0 International License. Read Full License 


\section{Abstract}

Background: Acute respiratory distress syndrome (ARDS) is a heterogeneous disease with extremely high mortality. We hypothesized that the serum $\beta 2$-microglobulin ( $\beta 2 M G$ ) level would be elevated and be an independent risk factor for 28-day mortality in patients with ARDS caused by bacterial infection.

Methods: We retrospectively enrolled 257 patients with ARDS caused by bacterial infection from January 1, 2015 to February 28, 2021. Patients were followed for up to 28 days and were divided into a survival group and non-survival group according to their clinical outcomes. The serum $\beta 2 M G$ levels and other clinical data were collected. The relationship between $\beta 2 M G$ levels and 28-day mortality was explored by performing a Cox regression analysis adjusted for age, updated Charlson comorbidity index, disorders of consciousness, septic shock, albumin level, cardiac troponin I level, procalcitonin level, lactic acid level, prothrombin time, partial pressure of arterial oxygen/fraction of inspired oxygen ratio, creatinine clearance rate, acute kidney injury and Sequential Organ Failure Assessment.

Results: In this cohort, 96 patients died in 28 days, yielding a 28-day mortality of $37.4 \%$. The median level of serum $\beta 2 M G$ for all enrolled patients was 4.7 (interquartile range [IQR]:2.9 - 8.5) mg/L. Higher $\beta 2 M G$ levels were significantly associated with 28-day mortality when the $32 \mathrm{MG}$ level was analysed as a continuous variable (hazard ratio [HR]: 1.054; $95 \%$ confidence interval $[\mathrm{Cl}]: 1.005-1.105 ; P=0.031$ ) and when it was categorized into tertiles (HR: 3.239; $95 \% \mathrm{Cl}$ : $1.177-8.913 ; P=0.023)$. The $\beta 2 \mathrm{MG}$ level exhibited a high diagnostic accuracy for predicting 28-day mortality (area under the curve [AUC] = 0.732; 95\% Cl:0.673-0.785; sensitivity:74.0\%; specificity:64.0\%; $P<0.001)$.

Conclusions: The level of serum $\beta 2 M G$ is elevated and is an independent risk factor of 28-day mortality in patients with ARDS caused by bacterial infection.

\section{Background}

Acute respiratory distress syndrome (ARDS) is a heterogeneous disease process that may be triggered by a variety of direct or indirect pulmonary injuries, such as pneumonia, aspiration, chest trauma, sepsis, and acute pancreatitis. Despite the use of low tidal volume ventilation, conservative liquid strategies, and extracorporeal membrane oxygenation, the rate of mortality due to ARDS remains extremely high [1,2]. Early detection of prognostic risk factors is very important for reducing ARDS mortality. Numerous studies have attempted to define contributors to ARDS mortality, with conflicting results [1,3-5], which may be related to changes in clinical management strategy.

$\beta 2$-microglobulin ( $\beta 2 \mathrm{MG}$ ) is an 11.8-kDa, non-glycosylated polypeptide that is present in all nucleated cells [6]. As a low-molecular-weight protein, $\beta 2 M G$ is released into the circulation at a constant rate, freely filtered by the glomeruli, and completely reabsorbed and catabolized in the renal tubules. These properties may make it an ideal endogenous biomarker for estimating the glomerular filtration rate and acute kidney injury (AKI) [6-9]. Numerous studies have shown that the serum $\beta 2 \mathrm{MG}$ level is not only used in assessing renal function by estimating the glomerular filtration rate and monitoring the effects of 
treatment [10] but also associated with a number of clinical states, including chronic inflammatory diseases, malignancies, and adverse outcomes in chronic obstructive pulmonary disease (COPD), acute pulmonary embolism, and cardiovascular diseases even though patients with preserved renal function [11-16]. ARDS is accompanied by an overwhelming inflammatory response and severe organ dysfunction, especially AKI. We hypothesized that for patients with ARDS, the serum $\beta 2 M G$ levels would be elevated at the time of ARDS occurrence and would be related to poor prognosis independently.

\section{Methods}

\section{Ethical approval}

This study was conducted in accordance with the 1964 Helsinki Declaration and its later amendments or comparable ethical standards and was approved by the Ethics Committee of the Beijing Chao-Yang Hospital, Capital Medical University (No. 2020-ke-429). Oral informed consent was obtained from all subjects and/or their legal guardian(s).

\section{Study design and population}

We retrospectively enrolled adult patients (aged $\geq 18$ years old) with ARDS (in accordance with the Berlin definition) [1] caused by bacterial infection who were admitted into the Department of Pulmonary and Critical Care Medicine, Beijing Chao-Yang Hospital from January 1, 2015 to February 28, 2021. All patients were included consecutively. Patients who lacked $32 M G$ data and patients with ARDS induced by causes other than bacterial infection were excluded. Other exclusion criteria included diseases that have a great impact on death, such as active malignant tumour, cerebral stroke, acute myocardial infarction, serious trauma, and a major operation (defined as lasting longer than 45 minutes) within the past month. Enrolled patients were followed for up to 28 days from diagnosis by the hospital electronic information system or by telephone and were divided into the survival group and non-survival group according to their clinical outcomes. A flow chart of patient enrolment and outcomes is shown in Figure 1.

\section{Clinical data collection}

Data, which included demographic information, clinical history (medical history, exposure history, underlying comorbidities), symptoms, vital signs and laboratory findings within 24 hours after ARDS diagnosis, treatments, complications, and patient survival at 28 days post-diagnosis, were collected from the medical records of the enrolled patients and analysed.

The levels of serum $\beta 2 \mathrm{MG}$, serum creatinine (Scr), albumin, total bilirubin (TBIL), alanine aminotransferase (ALT), and fasting plasma glucose (FPG) were measured using Latex immune turbidity and Oxidase method by Beckman Coulter UniCel DXC800 (Beckman Coulter, Inc., USA), and the normal range of $\beta 2 M G$ was $(1.0$ - 3.0) $\mathrm{mg} / \mathrm{L}$. The levels of $\mathrm{N}$-terminal pro-brain natriuretic peptide (NT-proBNP) 
and cardiac troponin I (cTnl) were measured using a fluorescence immunoassay (TZ-310 Dry fluorescence immunoassay; ReLIA Biotechnologies Ltd., China). White blood cell (WBC) counts were performed using an XT-1800i automatic haematology analyser (SYSMEX Co., Ltd, Japan). The C-reactive protein (CRP) levels were measured using a solid-phase sandwich format immunometric assay by NycoCardTM READER II (Alere Technologies AS, Norway). The procalcitonin (PCT) levels were measured by performing an immunochromatographic assay by B.R.A.H.M.S GmbH (Thermo Fisher Scientific Inc., Germany). The prothrombin time (PT) was measured using a coagulation method by Instrumentation Laboratory (Wofen medical device Trading Co., Ltd, USA). The lactic acid levels and partial pressure of arterial oxygen $\left(\mathrm{PaO}_{2}\right)$ were measured via spectrophotometry performed by an $\mathrm{ABL} 90$ blood gas analyser (Radiometer Medical ApS, Denmark). Body mass index (BMI) was calculated with the formula: $\mathrm{BMI}=$ weight $(\mathrm{kg}) /$ height $(\mathrm{m})^{2}$. We estimated the creatinine clearance rate $(\mathrm{Ccr})(\mathrm{mL} / \mathrm{min})$ with the CockroftGault equation: $\mathrm{Ccr}=([140-$ age in years $] \times$ body weight in $\mathrm{kg}) /(72 \times \mathrm{Scr}$ in $\mathrm{mg} / \mathrm{dL})$. For women, the calculated values were multiplied by 0.85 .

\section{Definitions}

ARDS was defined as described in the Berlin definition [1]. Patients were divided into three groups according to their oxygenation levels [1]: (1) Mild: $200 \mathrm{mmHg}(1 \mathrm{mmHg}=0.133 \mathrm{kPa})<$ $\mathrm{PaO}_{2} / \mathrm{FiO}_{2}$ (fraction of inspired oxygen) $\leq 300 \mathrm{mmHg}$ with positive end-expiratory pressure (PEEP) or continuous positive airway pressure (CPAP) $\geq 5 \mathrm{cmH}_{2} \mathrm{O}\left(1 \mathrm{cmH}_{2} \mathrm{O}=0.098 \mathrm{kPa}\right)$; (2) Moderate: $100 \mathrm{mmHg}<\mathrm{PaO}_{2} / \mathrm{FiO}_{2} \leq 200 \mathrm{mmHg}$ with PEEP $\geq 5 \mathrm{cmH}_{2} \mathrm{O}$; and (3) Severe: $\mathrm{PaO}_{2} / \mathrm{FiO}_{2} \leq 100 \mathrm{mmHg}$ with PEEP $\geq 5 \mathrm{cmH}_{2} \mathrm{O}$. The severity of comorbid diseases, such as coronary heart disease, congestive heart failure, cerebrovascular disease, diabetes mellitus, dementia, connective tissue disease, liver disease, and kidney disease, was recorded and scored in accordance with the Charlson comorbidity index updated by Quan et al. (updated CCI) [17]. Disorders of consciousness were identified in accordance with the Glasgow Coma Scale [18]. Septic shock was defined in accordance with the Third International Consensus Definitions for Sepsis and Septic Shock (Sepsis-3) [19]. AKI was defined in accordance with the Kidney Disease: Improving Global Outcomes (KDIGO) clinical practice guidelines (i.e., Scr levels increased by $\geq 0.3 \mathrm{mg} / \mathrm{dL}[\geq 26.5 \mu \mathrm{mol} / \mathrm{L}]$ within 48 hours or by 1.5 times of the baseline level within seven days) [20]. We applied the Sequential Organ Failure Assessment (SOFA) score to assess the disease severity [21].

\section{Statistical analyses}

Categorical variables are described as numbers and percentages (\%), and continuous variables are described as the mean and standard deviation (SD) or the median and interquartile range (IQR). The Shapiro-Wilk test was used to verify normality. Differences between the survival and non-survival groups were assessed by the two-sample $t$-test for normally distributed continuous variables, the Mann-Whitney $U$ test for non-normally distributed continuous variables, or the $\chi^{2}$ test for categorical variables. A 
rank correlation analysis was used to analyse the correlation between $\beta 2 \mathrm{MG}$ levels and other basic variables. Both univariate and multivariate Cox regression analyses were applied to evaluate the relationship between risk factors and 28-day mortality. Results are presented as hazard ratios (HRs) with $95 \%$ confidence intervals (Cls). Serum $\beta 2 \mathrm{MG}$ levels were adjusted for age, updated $\mathrm{CCl}$, disturbance of consciousness, septic shock, serum albumin levels, cTnl levels, PCT levels, PT, lactic acid levels, $\mathrm{PaO}_{2} / \mathrm{FiO}_{2}$ ratio, $\mathrm{Ccr}, \mathrm{AKI}$ and SOFA score in the multivariate Cox regression analysis. Survival rates grouped by $\beta 2 \mathrm{MG}$ tertiles are presented as cumulative survival curves adjusted for the abovementioned variables. Receiver operating characteristic (ROC) analyses were performed to calculate the sensitivity and specificity of risk factors for predicting 28-day mortality. The areas under receiver operating characteristics curves (ROC-AUCs) for different risk factors were compared using the method of DeLong et al. (1988) by MedCalc [22]. All other statistical analyses were performed using SPSS version 21.0 (Statistical Package for the Social Sciences, Chicago, IL USA). All tests were two-tailed; differences with a value of $P<0.05$ were considered statistically significant.

\section{Results}

\section{Patient enrolment}

A total of 257patients with ARDS were enrolled in this study.A flow chart of patient enrolment and outcomes is shown in Figure1.

\section{Demographic and clinicalcharacteristics ofsurvivorsvs non- survivors}

For all the 257 patients, 189 (73.5\%) had a level of serum $32 \mathrm{MG}>3.0 \mathrm{mg} / \mathrm{L}$. Table 1 shows the demographic andclinicalcharacteristics ofthe enrolled patients. In this cohort, 161 patients survived and 96 patients died within 28 days after the diagnosis of ARDS, yielding a 28-day mortality rate of $37.4 \%$. The median level of $\beta 2 M G$ for all patients with ARDS, regardless of their 28-day survival, was 4.7 (IQR:2.9 - 8.5) $\mathrm{mg} / \mathrm{L}$.Compared with the non-survivors, the survivors were younger $(P=0.002)$ and had lower updated CCls $(P<0.001)$, lower serum $\beta 2$ MG levels $(P<0.001)$, lower $\mathrm{Scr}$ levels $(P<0.001)$, lower $\mathrm{cTnl}$ levels $(P=0.001)$, lowerNT-proBNP levels $(P<0.001)$, lower PCT levels $(P=0.008)$, lowerlactic acid levels $(P<0.001)$, shorter PTs $(P=0.001)$, higher $\operatorname{Ccr}(P<0.001)$, higheralbumin levels $(P=0.002)$, and higher $\mathrm{PaO}_{2} / \mathrm{FiO}_{2}$ ratios $(P<0.001)$.Survivors also hadlower SOFA scores $(P<0.001)$ than non-survivors. More non-survivors had septic shock $(P=0.001)$ and AKI $(P<0.001)$ than survivors. There was no difference in the duration of mechanical ventilation (MV) between survivors and non-survivors $(P=0.514)$.

\section{Analyses of $\beta 2 \mathrm{MG}$ and other variables by rank correlation}


The serum $\beta 2 \mathrm{MG}$ levelswere positively correlated with age,updated CCl,disorders of consciousness,septic shock,cTnl levels,PCTlevels,lactic acidlevels, PT,AKI and SOFA scores, and negativelycorrelated withalbuminlevel, $\mathrm{PaO}_{2} / \mathrm{FiO}_{2}$ ratio and $\mathrm{Ccr}(P<0.05$ for all). Of the 257 patients in this study, $173(67.3 \%)$ had a CRP level equal to $120 \mathrm{mg} / \mathrm{mL}$ (the upper limit value for CRP testing in our laboratory at that time), and therefore we further analysed the 84 patients with a CRP level of $<120 \mathrm{mg} / \mathrm{mL}$ and found a significant positive correlation between the serum $32 \mathrm{MG}$ levels and CRP levels (Spearman correlation coefficient: 0.547; $P<0.001$ ) (Table 2).

\section{Univariate and multivariate survival analyses}

A univariate Cox regression analysis revealed thatthe level ofserum $32 \mathrm{MGis}$ apredictor of 28-day mortality in patients with ARDS (HR: 1.099; 95\% Cl: $1.068-1.131 ; P<0.001)$ (Table 3). Other predictors of 28-day mortality in these patients included age, updated $\mathrm{CCl}$,disorders of consciousness,septic shock, albuminlevel,PCTlevel,lactic acidlevel, $\mathrm{PT}, \mathrm{PaO}_{2} / \mathrm{FiO}_{2}$ ratio,Scrlevel,Ccr, AKI and SOFA score $(P<0.05$ for all).

Since there was similar clinical significance and a significant negative correlation between Scr and Ccr (Spearman correlation coefficient: - 0.887; $P<0.001$ ), to reduce data duplication, we did not include Scr into the multivariate Cox proportional hazards analysis. A higher $32 \mathrm{MG}$ level was significantly associated with 28-day mortality after adjusting for age, updated $\mathrm{CCl}$, disorders of consciousness, septic shock, albumin level, cTnl level, PCT level, lactic acid level, $\mathrm{PT}, \mathrm{PaO}_{2} / \mathrm{FiO}_{2}$ ratio, $\mathrm{Ccr}$, AKI and SOFA score (HR: 1.054; 95\% Cl: $1.005-1.105 ; P=0.031$ ) (Table 3).

When stratified by serum $32 \mathrm{MG}$ level tertiles, the 28-day mortality from the lowest to highest tertile was $12.5 \%$ (12/85), 38.5\% (37/88), and 49.0\% (47/84), respectively. The mortality risk was significantly higher in the highest category group (HR: 3.239; 95\% Cl: $1.177-8.913 ; P=0.023)$ after adjusting for age, updated $\mathrm{CCl}$, disorders of consciousness, septic shock, albumin level, CTnl level, PCT level, lactic acid level, $\mathrm{PT}, \mathrm{PaO}_{2} / \mathrm{FiO}_{2}$ ratio, $\mathrm{Ccr}, \mathrm{AKI}$ and SOFA score (Figure 2).

\section{Multivariate survival analysesstratified by $\mathrm{Ccr}$}

Further stratified analyses according to Ccr showed that serum $\beta 2 \mathrm{MG}$ level was independently associated with 28-day mortality not only in patients with $\mathrm{Ccr} \leq 60 \mathrm{~mL} / \mathrm{min}$ (HR: 1.054; 95\% Cl: $1.008-1.102 ; P=$ 0.022 ) but also in patients with $\mathrm{Ccr}>60 \mathrm{~mL} / \mathrm{min}$ (HR: 1.439; 95\% Cl: $1.047-1.979 ; P=0.025)$ (Table 4).

\section{Theprognosticvalue of serum $\beta 2 \mathrm{MG}$ levels on28- daymortality}


Theserum $\beta 2 \mathrm{MG}$ levelshowedadiagnostic accuracy for prediction for mortality $(\mathrm{AUC}=0.732 ; 95 \%$ Cl:0.673- 0.785; sensitivity:74.0\%, specificity: $64.0 \%$; $P<0.001)$ superior to that of $\mathrm{PaO}_{2} / \mathrm{FiO}{ }_{2}$ ratio(AUC= 0.633; 95\% Cl: 0.570- 0.692; sensitivity:71.9\%, specificity: 50.3\%; $P<0.001 ; P=0.032$ for these two curves), and not inferior to SOFA score (AUC=0.701; 95\% Cl: $0.641-0.756$; sensitivity: $60.4 \%$, specificity:68.3\%; $P<$ $0.001 ; P=0.313$ for these two curves) (Figure 3 ), when the cut-off value of the serum $\beta 2 \mathrm{MG}$ level was 4.6 $\mathrm{mg} / \mathrm{L}$.

\section{Discussion}

This study observed that the levels of serum $32 \mathrm{MG}$ in patients with ARDS caused by bacterial infection were elevated and were significantly higher in non-survivors than in survivors. A multivariate Cox proportional hazards analysis revealed that the serum $32 \mathrm{MG}$ level is an independent predictor for 28-day mortality in patients with ARDS, after adjusting for age, updated $\mathrm{CCl}$, disorders of consciousness, septic shock, albumin level, cTnl level, PCT level, PT, lactic acid level, $\mathrm{PaO}_{2} / \mathrm{FiO}_{2}$ ratio, Ccr, AKI and SOFA score. To our knowledge, this is an earlier report suggesting that the serum $\beta 2 \mathrm{MG}$ level might have a predictive value for the outcomes of patients with ARDS caused by bacterial infection.

The level of serum $\beta 2 M G$ depends on the factors of production (non-kidney factors) and elimination (kidney factors). Due to these properties, $\beta 2 \mathrm{MG}$ is not only an ideal endogenous biomarker for estimating the glomerular filtration rate and AKI [6-9] and the adverse outcomes of chronic kidney disease [23], but also associated with a number of clinical states beyond kidney disease [11-16]. Several previous studies have shown that levels of serum $\beta 2 \mathrm{MG}$ are higher in patients with inflammatory bowel disease or systemic lupus erythematosus than in healthy controls, suggesting that it might also be a useful biomarker for the assessment of these autoimmune diseases [16, 24]. Some research has suggested that $\beta 2 \mathrm{MG}$ is probably a general biomarker that reflects acute or chronic changes during inflammation and infection [25-27]. In addition, elevated levels of serum $\beta 2 M G$ have been also observed in patients with haemato-oncological pathology and solid tumours despite their preserved renal function $[11,28]$. Levels of serum $\beta 2 \mathrm{MG}$ are independently associated with major cardiovascular events and mortality in the general population as well as in elderly patients and in patients with acute heart failure who do not have severe renal insufficiency $[13,15,29]$. Studies have shown that serum $\beta 2 M G$ levels are also associated with poor outcomes in patients with COPD and in patients with acute pulmonary embolism [12, 14].

ARDS is a clinical syndrome with extremely high mortality, characterized by severe hypoxemia and an overwhelming inflammatory response, accompanied by multiple organ dysfunctions. Kohanpour et al. stated that an increase in serum $\beta 2 \mathrm{MG}$ levels can occur with physical exercise under hypoxic conditions [30]. Hadzimuratovic et al. observed increased serum $\beta 2 M G$ levels in neonatal asphyxia [31]. These findings suggest that elevated serum $\beta 2 M G$ levels are associated with hypoxemia. Some studies have found that an increase in serum $\beta 2 \mathrm{MG}$ levels is also present during infectious diseases as well as during inflammatory responses $[25,27]$. In this study, $189(73.5 \%)$ patients had a level of serum $\beta 2 M G>$ $3.0 \mathrm{mg} / \mathrm{L}$, and the median serum $\beta 2 \mathrm{MG}$ levels were found to be elevated in patients with bacterial 
infection-induced ARDS. A rank correlation analysis revealed that the serum $\beta 2 M G$ levels were negatively correlated with the $\mathrm{PaO}_{2} / \mathrm{FiO}_{2}$ ratio and positively correlated with the PCT levels and CRP levels. These correlations suggest that elevated serum $\beta 2 \mathrm{MG}$ levels during ARDS may partially be associated with hypoxemia as well as with inflammation and infection. In addition, ARDS is often accompanied by organ dysfunctions, especially AKI. In this research, more than half of the patients developed AKI, accompanied by a decline in glomerular filtration rate (median $\mathrm{Ccr} 43.0 \mathrm{~mL} / \mathrm{min}$ ), which may lead to decreased clearance of serum $32 \mathrm{MG}$. Altogether, in case of ARDS caused by bacterial infection, severe hypoxemia, infection, inflammatory responses, as well as the impairment of kidney function, result in increased $\beta 2 M G$ production and decreased renal eliminate, ultimately leading to elevated serum $\beta 2 M G$ levels, which are positively correlated with disease severity.

After adjusting for age, updated $\mathrm{CCl}$, disorders of consciousness, septic shock, albumin level, cTnl level, PCT level, $\mathrm{PT}$, lactic acid level, $\mathrm{PaO}_{2} / \mathrm{FiO}_{2}$ ratio, $\mathrm{Ccr}$, AKI and SOFA score, the $\beta 2 \mathrm{MG}$ level was independently associated with 28-day mortality in patients with ARDS. Further stratified analyses revealed that serum $\beta 2 \mathrm{MG}$ level was independently associated with 28-day mortality regardless of $\mathrm{Ccr} \leq$ $60 \mathrm{~mL} / \mathrm{min}$ or $\mathrm{Ccr}>60 \mathrm{~mL} / \mathrm{min}$ [32]. It is generally believed that serum $\beta 2 \mathrm{MG}$ level is associated with renal function injury and its adverse prognosis $[9,23]$. At present, the non-renal factors related to serum $\beta 2 M G$ and mortality are not clear. Several studies have shown that $\beta 2 M G$ can act as an inflammatory cytokine and fibrosis related factor [33] and participate in the development of kidney and liver fibrosis [34, 35]. Under pressure overload, $\beta 2 M G$ promotes cardiac fibrosis and activation of cardiac fibroblasts [36]. Research by Wu et al showed that increased serum $32 \mathrm{MG}$ expression led to epithelial mesenchymal transition, alveolar wall/septal thicken, and pulmonary fibrosis in a rat model of COPD, and lead to decreased diffusion capacity in the lungs of patients with COPD [37]. These results suggest a possible direct pathogenic role for circulating $\beta 2 M G$. It is unknown currently whether a similar pathogenic role exists for $\beta 2 M G$ in patients with ARDS. Kono et al reported that direct hemoperfusion with a $\beta 2 \mathrm{MG}$ selective adsorbent column can eliminates inflammatory cytokines and improves pulmonary oxygenation in patients with ARDS/acute lung injury [38]. This supports a possible pathogenic role for circulating $\beta 2 M G$ in ARDS.

We applied the updated $\mathrm{CCI}$ [17] to assess comorbidities of enrolled patients, including coronary heart disease, congestive heart failure, cerebrovascular disease, diabetes mellitus, dementia, connective tissue disease, liver disease, and kidney disease, and found that it was significantly associated with 28-day mortality in patients with bacterial infection-induced ARDS. This result is consistent with previous research [39].

Severe hypoxemia is a characteristic manifestation of ARDS. The $\mathrm{PaO}_{2} / \mathrm{FiO}_{2}$ ratio is an integral part of the assessment of patients with ARDS and is an important criterion for severity grading in the Berlin standard [1]. Although some studies have found that the $\mathrm{PaO}_{2} / \mathrm{FiO}_{2}$ ratio is not a good prognostic factor for ARDS [4], as an important indicator of the severity of lung injury, however, most studies have shown that the decreased $\mathrm{PaO}_{2} / \mathrm{FiO}_{2}$ ratio is associated with increased mortality or failure of non-invasive $\mathrm{MV}$ in 
patients with ARDS $[19,40,41]$. Similarly, our study showed that the $\mathrm{PaO}_{2} / \mathrm{FiO}_{2}$ ratio was a protective factor for the prognosis of patients with ARDS.

In this study, SOFA score was also independently associated with 28-day mortality in patients with ARDS. Both the serum $32 M G$ level and the SOFA score exhibited high diagnostic accuracy for predicting 28day mortality with no significantly difference. And the diagnostic accuracy of serum $\beta 2 M G$ level was not inferior to the combination of serum $\beta 2 \mathrm{MG}$ level and SOFA score. The serum $\beta 2 \mathrm{MG}$ level showed satisfactory forecasting ability for mortality significantly higher than that of the $\mathrm{PaO}_{2} / \mathrm{FiO}_{2}$ ratio. Since the $\mathrm{PaO}_{2} / \mathrm{FiO}_{2}$ ratio only reflects the severity of lung injury, while serum $\beta 2 \mathrm{MG}$ level is associated with hypoxemia, infection, systemic inflammatory response, renal injury and more comprehensively reacts the overall condition of ARDS. The diagnostic value of serum $32 M G$ for mortality in patients with ARDS is better than that of $\mathrm{PaO}_{2} / \mathrm{FiO}_{2}$ ratio and is not inferior to SOFA score, which is commonly used as critical care score. Therefore, the serum $\beta 2 M G$ may be an ideal screening tool for mortality in patients with ARDS as it can be easily and economically measured.

It is also worth mentioning that there are several limitations in the present study. First, this research was conducted in a single centre, which could have biased its results. Second, owing to the small sample size in this study, to avoid overfitting, only a limited number of clinical variables were entered into the Cox regression analysis, and it is possible that some potentially relevant variables were not evaluated. Third,

although the ROC curve in our study showed predictive value for the outcome of patients with ARDS, we could not verify the applicability of this clinical indicator because of the small sample size. Future prospective studies will be necessary to identify the causes of elevated $\beta 2 M G$ and the specific mechanism associated with prognosis, to verify the prognostic value of serum $\beta 2 \mathrm{MG}$ levels in patients with ARDS caused by bacterial infection.

\section{Conclusions}

The level of serum $\beta 2 M G$, measured within 24 hours after the diagnosis of ARDS, is elevated and may be a promising early biomarker of prognosis in patients with ARDS caused by bacterial infection. Further prospective research will be necessary to verify this finding, which may help clinicians undertake timely and effective programmes to improve the outcomes of these patients.

\section{Abbreviations}

ARDS, acute respiratory distress syndrome; $\beta 2 M G, \beta 2$-microglobulin; AKI, acute kidney injury; Scr, serum creatinine; BUN, blood urea nitrogen; TBIL, total bilirubin; ALT, alanine aminotransferase; FPG, fasting plasma glucose; NT-proBNP, N-terminal pro-brain natriuretic peptide; cTnl, cardiac troponin I; WBC, white blood cell; CRP, C-reactive protein; PCT, procalcitonin; PT, prothrombin time; BMI, body mass index; $\mathrm{Ccr}$, creatinine clearance rate; $\mathrm{PaO}_{2}$, partial pressure of arterial oxygen; $\mathrm{FiO}_{2}$, fraction of inspired oxygen; PEEP, positive end-expiratory pressure; CPAP, continuous positive airway pressure; $\mathrm{CCl}$, Charlson comorbidity index; APACHE, Acute Physiology and Chronic Health Evaluation; SOFA, Sequential Organ 
Failure Assessment; MV, mechanical ventilation; SD, standard deviation; IQR, interquartile range; HR, hazard ratio; $\mathrm{Cl}$, confidence interval; $\mathrm{ROC}$, receiver operating characteristic.

\section{Declarations}

\section{Ethics and approval and consent to participate}

This retrospective study involving human participants was approved by the ethics committee of the Beijing Chao-Yang Hospital, Capital Medical University (2020-ke-429) and was in accordance with 1964 Helsinki Declaration and its later amendments or comparable ethical standards. Oral informed consent was obtained from all subjects and/or their legal guardian(s).

\section{Consent for publication}

Not applicable.

\section{Availability of data and materials}

All data analysed during the study are presented in the main manuscript. The anonymous dataset is available from the corresponding author upon reasonable request.

\section{Competing interests}

The authors declare that they have no competing interests.

\section{Funding}

This research was supported by the multicenter clinical research verification of nasal high flow humidification oxygen therapy equipment (Grant NO. 2019YFC0121704 to Dr Jing Wang).

\section{Authors' contributions}

NC, JW and LMZ contributed to the conception and design of the study. LMZ and JW took part in managing the research. XKF and CGJ contributed to the acquisition of data. All authors were involved in data analysis and interpretation and development of the manuscript. All authors read and approved the final manuscript. NC and XKF contributed equally to this article and shared first authorship. LMZ and JW contributed equally to this article and shared corresponding authorship. 


\section{Acknowledgements}

Not applicable.

\section{Author details}

${ }^{1}$ Department of Respiratory and Critical Care Medicine, Beijing Institute of Respiratory Medicine and Beijing Chao-Yang Hospital, Capital Medical University, Beijing, China; ${ }^{2}$ Department of Respiratory and Critical Care Medicine, Qinghai Provincial People's Hospital, Qinghai University, Xining, China

\section{References}

1. ARDS Definition Task Force RV, Rubenfeld GD, Thompson BT, et al. Acute Respiratory Distress Syndrome: The Berlin Definition. JAMA 2012; 307(23):2526-2533.

2. Bellani G, Laffey JG, Pham T, et al. Epidemiology, Patterns of Care, and Mortality for Patients With Acute Respiratory Distress Syndrome in Intensive Care Units in 50 Countries. JAMA 2016; 315(8):788-800.

3. Villar J, Ambrós A, Soler JA, et al. Age, Pa02/FIO2, and Plateau Pressure Score: A Proposal for a Simple Outcome Score in Patients With the Acute Respiratory Distress Syndrome. Crit Care Med 2016; 44(7):1361-1369.

4. Chen WL, Lin WT, Kung SC, et al. The Value of Oxygenation Saturation Index in Predicting the Outcomes of Patients with Acute Respiratory Distress Syndrome. J Clin Med 2018; 7(8).

5. Kamo T, Tasaka S, Suzuki T, et al. Prognostic values of the Berlin definition criteria, blood lactate level, and fibroproliferative changes on high-resolution computed tomography in ARDS patients. BMC Pulm Med 2019; 19(1):37.

6. Woitas RP, Stoffel-Wagner B, Poege U,et al. Low-molecular weight proteins as markers for glomerular filtration rate. Clin Chem 2001; 47(12):2179-2180.

7. Bianchi C, Donadio C, Tramonti G, et al. Reappraisal of serum beta2-microglobulin as marker of GFR. Ren Fail 2001; 23(3-4):419-429.

8. Zaleska-Kociecka M, Skrobisz A, Wojtkowska I, et al. Serum beta-2 microglobulin levels for predicting acute kidney injury complicating aortic valve replacement. Interact Cardiovasc ThoracSurg 2017; 25(4):533-540.

9. Wang $\mathrm{R}, \mathrm{Hu} \mathrm{H}, \mathrm{Hu} \mathrm{S}$,et al.ß2-microglobulin is an independent indicator of acute kidney injury and outcomes in patients with intracerebral hemorrhage. Medicine (Baltimore) 2020; 99(8):e19212.

10. Inker LA, Tighiouart $\mathrm{H}$, Coresh J, et al. GFR Estimation Using $\beta$-Trace Protein and $\beta 2$-Microglobulin in CKD. Am J Kidney Dis 2016; 67(1):40-48.

11. Bataille R, Durie BG, Grenier J. Serum beta2 microglobulin and survival duration in multiple myeloma: a simple reliable marker for staging. Br J Haemato/ 1983; 55(3):439-447. 
12. Kakavas S, Papanikolaou A, Balis E, et al. The prognostic efficacy of beta2-microglobulin in acute pulmonary embolism. Acute Med 2017; 16(2):52-59.

13. Wang HJ, Si QJ, Shi Y, et al. The prognostic values of beta-2 microglobulin for risks of cardiovascular events and mortality in the elderly patients with isolated systolic hypertension. J ResMed Sci 2018; 23:82.

14. Mao W, Wang J, Zhang L, et al. Serum $\beta 2$-Microglobulin is Associated with Mortality in Hospitalized Patients with Exacerbated Chronic Obstructive Pulmonary Disease. Int J ChronObstruct Pulmon Dis 2020; 15:723-732.

15. Shi F, Sun L, Kaptoge S. Association of beta-2-microglobulin and cardiovascular events and mortality: A systematic review and meta-analysis. Atherosclerosis 2021; 320:70-78.

16. Hermansen ML, Hummelshøj L, Lundsgaard D, et al. Increased serum $\beta 2$-microglobulin is associated with clinical and immunological markers of disease activity in systemic lupus erythematosus patients. Lupus 2012; 21(10):1098-1104.

17. Quan H, Li B, Couris CM, et al. Updating and validating the Charlson comorbidity index and score for risk adjustment in hospital discharge abstracts using data from 6 countries. Am J Epidemio/ 2011; 173(6):676-682.

18. Jones C. Glasgow coma scale. Am J Nurs 197; 79(9):1551-1553.

19. Singer M, Deutschman CS, Seymour CW, et al. The Third International Consensus Definitions for Sepsis and Septic Shock (Sepsis-3). JAMA 2016; 315(8):801-810.

20. Khwaja A. KDIGO clinical practice guidelines for acute kidney injury. Nephron Clin Pract 2012; 120(4):c179-c184.

21. Lambden S, Laterre PF, Levy MM, et al. The SOFA score-development, utility and challenges of accurate assessment in clinical trials. Crit Care 2019; 23(1):374.

22. DeLong ER, DeLong DM, Clarke-Pearson DL. Comparing the areas under two or more correlated receiver operating characteristic curves: a nonparametric approach. Biometrics 1988; 44(3):837-845.

23. Wu HC, Lee LC, Wang WJ. Associations among Serum Beta 2 Microglobulin, Malnutrition, Inflammation, and Advanced Cardiovascular Event in Patients with Chronic Kidney Disease. $J$ ClinLab Anal 2017; 31(3).

24. Yılmaz B, Köklü S, Yüksel O, et al. Serum beta 2-microglobulin as a biomarker in inflammatory bowel disease. World J Gastroenterol 2014; 20(31):10916-10920.

25. Nesović-Ostojić J, Klun I, Vujanić M, et al. Serum beta2-microglobulin as a marker of congenital toxoplasmosis and cytomegalovirus infection in preterm neonates. Neonatology 2008; 94(3):183186.

26. Li L, Dong M, Wang XG. The Implication and Significance of Beta 2 Microglobulin: A Conservative Multifunctional Regulator. Chin Med J (Engl) 2016; 129(4):448-455.

27. Cai X, Xu Q, Zhou C, et al. Distribution characteristics of serum $\beta 2$-microglobulin between viral and bacterial lower respiratory tract infections: a retrospective study. Peer J 2020; 8:e9814. 
28. Josson S, Nomura T, Lin JT, et al.ß2-microglobulin induces epithelial to mesenchymal transition and confers cancer lethality and bone metastasis in human cancer cells. Cancer Res 2011; 71(7):26002610.

29. Kawai K, Kawashima S, Miyazaki T, et al. Serum beta2-microglobulin concentration as a novel marker to distinguish levels of risk in acute heart failure patients. J Cardiol 2010; 55(1):99-107.

30. Kohanpour MA, Sanavi S, Peeri M, et al. Effect of submaximal aerobic exercise in hypoxic conditions on proteinuria and hematuria in physically trained young men. Iran J Kidney Dis 2012; 6(3):192-197.

31. Hadzimuratovic E, Skrablin S, Hadzimuratovic A, et al. Postasphyxial renal injury in newborns as a prognostic factor of neurological outcome. J Matern Fetal Neonatal Med 2014; 27(4):407-410.

32. Stevens PE, Levin A. Evaluation and management of chronic kidney disease: synopsis of the kidney disease: improving global outcomes 2012 clinical practice guideline. Ann Intern Med 2013; 158(11):825-830.

33. Filiano AJ, Kipnis J. Breaking bad blood: $\beta 2$-microglobulin as a pro-aging factor in blood. Nat Med 2015; 21(8):844-845.

34. Zhang A, Wang B, Yang $M$, et al.ß2-microglobulin induces epithelial-mesenchymal transition in human renal proximal tubule epithelial cells in vitro. BMC Nephrol 2015; 16:60.

35. Chen J, Li HY, Wang D, et al. Delphinidin protects $\beta 2 \mathrm{~m}$-/Thy $1+$ bone marrow-derived hepatocyte stem cells against TGF- $\beta 1$-induced oxidative stress and apoptosis through the PI3K/Akt pathway in vitro. Chem Biol Interact 2019; 297:109-118.

36. Li Y, Zhang X, Li L, et al. Mechanical stresses induce paracrine $\beta$-2 microglobulin from cardiomyocytes to activate cardiac fibroblasts through epidermal growth factor receptor. Clin Sci(Lond) 2018; 132(16):1855-1874.

37. Wu Z, Yan M, Zhang M, et al. $\beta 2$-microglobulin as a biomarker of pulmonary fibrosis development in COPD patients. Aging (Albany NY) 2020; 13(1):1251-1263.

38. Kono K, Toda S, Hora K,et al. Direct hemoperfusion with a beta2-microglobulin-selective adsorbent column eliminates inflammatory cytokines and improves pulmonary oxygenation. TherApher Dial 2009; 13(1):27-33.

39. Ternavasio-de la Vega HG, Castaño-Romero F, Ragozzino S, et al. The updated Charlson comorbidity index is a useful predictor of mortality in patients with Staphylococcus aureus bacteraemia. Epidemiol Infect 2018; 146(16):2122-2130.

40. Sehgal IS, Agarwal R, Dhooria S, et al. Risk stratification of acute respiratory distress syndrome using a PaO2: Fio2 threshold of $150 \mathrm{mmHg}$ : A retrospective analysis from an Indian intensive care unit. Lung India 2020; 37(6):473-478.

41. Villar J, Pérez-Méndez L, Basaldúa S, et al. A risk tertiles model for predicting mortality in patients with acute respiratory distress syndrome: age, plateau pressure, and $\mathrm{P}(\mathrm{aO}(2)) / \mathrm{F}(\mathrm{IO}(2))$ at $\mathrm{ARDS}$ onset can predict mortality. Respir Care 2011; 56(4):420-428.

\section{Tables}


Table 1

Demographic and clinical characteristics of patients with ARDS 


\begin{tabular}{|c|c|c|c|c|}
\hline $\begin{array}{l}\text { Clinical } \\
\text { characteristics }\end{array}$ & $\begin{array}{l}\text { Total ARDS } \\
(\mathrm{N}=257)\end{array}$ & $\begin{array}{l}\text { Survivors } \\
(n=161)\end{array}$ & $\begin{array}{l}\text { Non-Survivors } \\
(\mathrm{n}=96)\end{array}$ & $P$ value \\
\hline Age (years) & $70(57,80)$ & $68(55,77)$ & $74(62,81)$ & 0.002 \\
\hline Male, n (\%) & $167(65.0)$ & $102(63.4)$ & $65(67.7)$ & 0.479 \\
\hline $\mathrm{BMI}\left(\mathrm{kg} / \mathrm{m}^{2}\right)$ & $24.3 \pm 4.6$ & $24.4 \pm 4.4$ & $24.3 \pm 5.0$ & 0.860 \\
\hline $\begin{array}{l}\text { Current smoker, } \\
\text { n (\%) }\end{array}$ & $107(41.6)$ & $69(42.9)$ & $38(39.6)$ & 0.607 \\
\hline CCl updated & $2(1,3)$ & $1(0,3)$ & $2(1,3)$ & $<0.001$ \\
\hline $\begin{array}{l}\text { Disorders of consciousness, } n \\
(\%)\end{array}$ & $61(23.7)$ & $33(20.5)$ & $28(29.2)$ & 0.114 \\
\hline Septic shock, n (\%) & $127(49.4)$ & $67(41.6)$ & $60(62.5)$ & 0.001 \\
\hline$\beta 2 M G(m g / L)$ & $4.7(2.9,8.5)$ & $3.7(2.5,6.4)$ & $6.3(4.3,12.3)$ & $<0.001$ \\
\hline$\beta 2 M G$ level increased, $n$ (\%) & $189(73.5)$ & $102(63.4)$ & $96(90.6)$ & $<0.001$ \\
\hline $\operatorname{Scr}(\mu \mathrm{mol} / \mathrm{L})$ & $\begin{array}{l}113.0(67.4 \\
207.8)\end{array}$ & $\begin{array}{l}90.5(63.0 \\
190.8)\end{array}$ & $\begin{array}{l}139.4(92.3 \\
286.7)\end{array}$ & $<0.001$ \\
\hline $\operatorname{Ccr}(\mathrm{mL} / \mathrm{min})$ & $43.0(25.2,81.5)$ & $\begin{array}{l}55.9(29.8, \\
103.6)\end{array}$ & $33.2(18.6,57.9)$ & $<0.001$ \\
\hline $\mathrm{AKI}, \mathrm{n}(\%)$ & $154(59.9)$ & $82(50.9)$ & $72(75.0)$ & $<0.001$ \\
\hline Albumin $(\mathrm{g} / \mathrm{L})$ & $26.5(23.6,30.0)$ & $\begin{array}{l}27.1(24.1, \\
30.8)\end{array}$ & $25.1(22.0,29.3)$ & 0.002 \\
\hline TBIL $(\mu \mathrm{mol} / \mathrm{L})$ & $20.8(13.1,31.6)$ & $\begin{array}{l}20.8(12.7 \\
31.0)\end{array}$ & $20.8(13.2,35.2)$ & 0.674 \\
\hline $\operatorname{ALT}(\mathrm{U} / \mathrm{L})$ & $31.0(18.5,66.4)$ & $\begin{array}{l}29.7(17.8, \\
59.6)\end{array}$ & $32.9(18.8,84.5)$ & 0.337 \\
\hline cTnl (ng/mL) & $0.10(0.04,0.35)$ & $\begin{array}{l}0.10(0.03 \\
0.24)\end{array}$ & $0.14(0.06,0.53)$ & 0.001 \\
\hline \multirow[t]{2}{*}{ NT-proBNP (pg/mL) } & 1830.6 & 1212.7 & 2812.0 & $<0.001$ \\
\hline & $(557.8,4887.3)$ & $(325.8,4050.0)$ & $(1447.0,7078.3)$ & \\
\hline FPG (mmol/L) & $8.6(6.6,11.4)$ & $8.1(6.5,10.6)$ & $8.9(7.1,12.4)$ & 0.124 \\
\hline WBC $\left(\times 10^{9} / \mathrm{L}\right)$ & $16.5(11.7,21.3)$ & $\begin{array}{l}16.3(11.7, \\
21.0)\end{array}$ & $16.9(13.1,23.1)$ & 0.489 \\
\hline CPR (mg/L) & $120(98,120)$ & $120(86,120)$ & $120(102,120)$ & 0.595 \\
\hline РCT (ng/mL) & $5.6(0.8,18.4)$ & $3.7(0.4,15.4)$ & $6.3(1.9,24.6)$ & 0.008 \\
\hline
\end{tabular}




\begin{tabular}{|lllll|}
\hline PT $(\mathrm{s})$ & $13.9(12.7,15.8)$ & $13.8(12.5$, & $14.9(13.3,17.3)$ & 0.001 \\
\hline Lactic acid (mmol/L) & $1.8(1.3,2.7)$ & $1.6(1.1,2.3)$ & $2.3(1.5,4.0)$ & $<0.001$ \\
\hline $\mathrm{PaO}_{2} / \mathrm{FiO}_{2}$ ratio & $157(105,199)$ & $172(117,208)$ & $134(81,178)$ & $<$ \\
\hline Mild, $\mathrm{n}(\%)$ & $63(24.5)$ & $48(29.8)$ & $15(15.6)$ & $0.001^{*}$ \\
\hline Moderate, $\mathrm{n}(\%)$ & $131(51.0)$ & $86(53.4)$ & $45(46.9)$ & \\
\hline Severe, $\mathrm{n}(\%)$ & $63(24.5)$ & $27(16.8)$ & $36(37.5)$ & \\
\hline Duration of MV (days) & $8(5,17)$ & $8(5,18)$ & $8(4,16)$ & $0.001^{+}$ \\
\hline SOFA score & $8(5,10)$ & $7(4,9)$ & $9(7,12)$ & $<0.001$ \\
\hline
\end{tabular}

Data are the mean $\pm \mathrm{SD}$, median (IQR), or $\mathrm{n}(\%)$. P values comparing the Survivor and non-Survivor groups are from a 2-sample $t$-test, Mann-Whitney $U$ test, or $\chi^{2}$ test. Differences with values of $P<0.05$ were considered statistically significant.

${ }^{*} \chi^{2}$ test comparing the Survivor and non-Survivor groups. ${ }^{\dagger} \chi^{2}$ test comparing all subcategories.

Abbreviations: AKI, acute kidney injury; ALT, alanine aminotransferase; ARDS, acute respiratory distress syndrome; $\mathrm{BMI}$, body mass index; $\beta 2 \mathrm{MG}, \beta 2$-microglobulin; $\mathrm{CCl}$, Charlson comorbidity index; $\mathrm{Ccr}$, creatinine clearance rate; $\mathrm{CRP}$, C-reactive protein; $\mathrm{CTnl}$, cardiac troponin $\mathrm{l} ; \mathrm{FiO}_{2}$, fraction of inspired oxygen; FPG, fasting plasma glucose; IQR, interquartile range; Mild, $200 \mathrm{mmHg}<\mathrm{PaO}_{2} / \mathrm{FiO}_{2}$ ratio $\leq 300 \mathrm{mmHg}$; Moderate, $100 \mathrm{mmHg}<\mathrm{PaO}_{2} / \mathrm{FiO}_{2}$ ratio $\leq 200 \mathrm{mmHg}$; MV, mechanical ventilation; NTproBNP, $\mathrm{N}$-terminal pro-brain natriuretic peptide; $\mathrm{PaO}_{2}$, partial pressure of arterial oxygen; $\mathrm{PCT}$, procalcitonin; PT, prothrombin time; Scr, serum creatinine; SD, standard deviation; Severe, $\mathrm{PaO}_{2} / \mathrm{FiO}_{2}$ ratio $\leq 100$ mmHg; SOFA, Sequential Organ Failure Assessment; TBIL, total bilirubin; WBC, white blood cell.

\section{Table 2}

\section{Rank correlation between $\beta 2 M G$ and basic variables in patients with ARDS}




\begin{tabular}{|c|c|c|}
\hline Variables & Correlation coefficient & $P$ value \\
\hline Age (years) & 0.246 & $<0.001$ \\
\hline Male & -0.031 & 0.618 \\
\hline $\mathrm{BMI}\left(\mathrm{kg} / \mathrm{m}^{2}\right)$ & 0.007 & 0.916 \\
\hline Current smoker & -0.041 & 0.508 \\
\hline CCl updated & 0.204 & 0.001 \\
\hline Disturbance of consciousness & 0.166 & 0.008 \\
\hline Septic shock & 0.278 & $<0.001$ \\
\hline $\operatorname{Scr}(\mu \mathrm{mol} / \mathrm{L})$ & 0.821 & $<0.001$ \\
\hline $\operatorname{Ccr}(\mathrm{mL} / \mathrm{min})$ & -0.817 & $<0.001$ \\
\hline AKI & 0.696 & $<0.001$ \\
\hline Albumin (g/L) & -0.231 & $<0.001$ \\
\hline TBIL $(\mu \mathrm{mol} / \mathrm{L})$ & 0.082 & 0.189 \\
\hline $\mathrm{ALT}(\mathrm{U} / \mathrm{L})$ & -0.057 & 0.362 \\
\hline cTnl (ng/mL) & 0.362 & $<0.001$ \\
\hline NT-proBNP (pg/mL) & 0.557 & $<0.001$ \\
\hline FPG (mmol/L) & 0.003 & 0.963 \\
\hline WBC $\left(\times 10^{9} / L\right)$ & 0.153 & 0.014 \\
\hline CRP (mg/L) & 0.113 & 0.071 \\
\hline $\mathrm{CRP}^{\star}(\mathrm{mg} / \mathrm{L})$ & 0.547 & $<0.001$ \\
\hline РCT (ng/mL) & 0.421 & $<0.001$ \\
\hline PT (s) & 0.202 & 0.001 \\
\hline Lactic acid (mmol/L) & 0.214 & 0.001 \\
\hline $\mathrm{PaO}_{2} / \mathrm{FiO}_{2}$ ratio & -0.171 & 0.006 \\
\hline SOFA score & 0.611 & $<0.001$ \\
\hline
\end{tabular}

$P<0.05$ were considered statistically significant.

${ }^{*}$ CRP level of $<120 \mathrm{mg} / \mathrm{L}$. 
Abbreviations: AKI, acute kidney injury; ALT, alanine aminotransferase; ARDS, acute respiratory distress syndrome; $\mathrm{BMI}$, body mass index; $\beta 2 \mathrm{MG}, \beta 2$-microglobulin; $\mathrm{CCl}$, Charlson comorbidity index; $\mathrm{Ccr}$, creatinine clearance rate; $\mathrm{CRP}$, C-reactive protein; $\mathrm{CTnl}$, cardiac troponin l; $\mathrm{FiO}_{2}$, fraction of inspired oxygen; FPG, fasting plasma glucose; NT-proBNP, N-terminal pro-brain natriuretic peptide; $\mathrm{PaO}_{2}$, partial pressure of arterial oxygen; PCT, procalcitonin; PT, prothrombin time; Scr, serum creatinine; SOFA, Sequential Organ Failure Assessment; TBIL, total bilirubin; WBC, white blood cell.

\section{Table 3}

Univariate and multivariate survival analysis of the 28-day mortality risk in patients with ARDS 


\begin{tabular}{|c|c|c|c|c|}
\hline Clinical characteristics & $\begin{array}{l}\text { Univariate HR } \\
(95 \% \mathrm{Cl})\end{array}$ & $P$ value & $\begin{array}{l}\text { Multivariate HR } \\
(95 \% \mathrm{Cl})\end{array}$ & $P$ value \\
\hline$\beta 2 M G(m g / L)$ & $1.099(1.068,1.131)$ & $<0.001$ & $1.054(1.005,1.105)$ & 0.031 \\
\hline Age (years) & $1.019(1.005,1.033)$ & 0.008 & $1.016(0.998,1.034)$ & 0.074 \\
\hline CCl updated & $1.231(1.097,1.381)$ & $<0.001$ & $1.176(1.033,1.340)$ & 0.014 \\
\hline Disorders of consciousness & $1.610(1.036,2.501)$ & 0.034 & $0.871(0.515,1.473)$ & 0.606 \\
\hline Septic shock & $2.043(1.351,3.090)$ & 0.001 & $0.996(0.602,1.648)$ & 0.988 \\
\hline Albumin $(\mathrm{g} / \mathrm{L})$ & $0.938(0.902,0.976)$ & 0.001 & $0.966(0.929,1.005)$ & 0.089 \\
\hline cTnl (ng/mL) & $1.044(0.950,1.147)$ & 0.374 & $1.003(0.879,1.144)$ & 0.966 \\
\hline PCT (ng/mL) & $1.021(1.003,1.039)$ & 0.022 & $1.002(0.982,1.023)$ & 0.828 \\
\hline PT (s) & $1.019(1.004,1.034)$ & 0.011 & $1.004(0.987,1.022)$ & 0.611 \\
\hline Lactic acid (mmol/L) & $1.104(1.062,1.146)$ & $<0.001$ & $1.022(0.976,1.071)$ & 0.350 \\
\hline $\mathrm{PaO}_{2} / \mathrm{FiO}_{2}$ ratio & $0.994(0.991,0.998)$ & 0.001 & $0.996(0.992,1.000)$ & 0.030 \\
\hline $\operatorname{Ccr}(\mathrm{mL} / \mathrm{min})$ & $0.986(0.979,0.992)$ & $<0.001$ & $1.002(0.989,1.016)$ & 0.715 \\
\hline AKI & $2.503(1.576,3.976)$ & $<0.001$ & $1.169(0.513,2.665)$ & 0.711 \\
\hline SOFA score & $1.146(1.096,1.199)$ & $<0.001$ & $1.087(1.000,1.182)$ & 0.049 \\
\hline Male & $1.143(0.745,1.753)$ & 0.542 & & \\
\hline BMI $\left(\mathrm{kg} / \mathrm{m}^{2}\right)$ & $0.988(0.943,1.034)$ & 0.604 & & \\
\hline Current smoker & $0.906(0.602,1.364)$ & 0.637 & & \\
\hline $\operatorname{Scr}(\mu \mathrm{mol} / \mathrm{L})$ & $1.002(1.001,1.003)$ & 0.001 & & \\
\hline TBIL $(\mu \mathrm{mol} / \mathrm{L})$ & $1.002(1.000,1.003)$ & 0.115 & & \\
\hline ALT (U/L) & $1.000(1.000,1.001)$ & 0.242 & & \\
\hline NT-proBNP (pg/mL) & $1.000(1.000,1.000)$ & 0.173 & & \\
\hline FPG (mmol/L) & $1.021(0.980,1.064)$ & 0.312 & & \\
\hline WBC $\left(\times 10^{9} / L\right)$ & $1.007(0.984,1.030)$ & 0.549 & & \\
\hline CRP (mg/L) & $1.006(0.998,1.015)$ & 0.151 & & \\
\hline
\end{tabular}

A Cox proportional hazards analysis was performed. Data are the HR $(95 \% \mathrm{Cl})$. Adjusted for age, updated $\mathrm{CCl}$, disorders of consciousness, septic shock, albumin, cTnl, procalcitonin, prothrombin time, lactic acid, $\mathrm{PaO}_{2} / \mathrm{FiO}_{2}$ ratio, $\mathrm{Ccr}, \mathrm{AKI}$ and SOFA score. $P<0.05$ were considered statistically significant. 
Abbreviations: AKI, acute kidney injury; ALT, alanine aminotransferase; ARDS, acute respiratory distress syndrome; $\mathrm{BMI}$, body mass index; $\beta 2 \mathrm{MG}, \beta 2$-microglobulin; $\mathrm{CCl}$, Charlson comorbidity

index; $\mathrm{Ccr}$, creatinine clearance rate; $\mathrm{Cl}$, confidence interval; $\mathrm{CRP}$, C-reactive protein; $\mathrm{CTnl}$, cardiac troponin l; $\mathrm{FiO}_{2}$, fraction of inspired oxygen; FPG, fasting plasma glucose; $\mathrm{HR}$, hazard ratio; NT-proBNP, N-terminal pro-brain natriuretic peptide; $\mathrm{PaO}_{2}$, partial pressure of arterial oxygen; $\mathrm{PCT}$, procalcitonin; $\mathrm{PT}$, prothrombin time; Scr, serum creatinine; SOFA, Sequential Organ Failure Assessment; TBIL, total bilirubin; WBC, white blood cell.

\section{Table 4}

Multivariate survival analysis of the 28-day mortality risk stratified by $\mathrm{Ccr}$ in patients with ARDS 


\begin{tabular}{|c|c|c|c|c|}
\hline \multirow[t]{2}{*}{ Clinical characteristics } & \multicolumn{2}{|c|}{$\mathrm{Ccr} \leq 60 \mathrm{~mL} / \mathrm{min}$ group $(\mathrm{n}=155)$} & \multicolumn{2}{|c|}{$\begin{array}{l}\text { Ccr }>60 \mathrm{~mL} / \mathrm{min} \text { group } \\
(\mathrm{n}=102)\end{array}$} \\
\hline & $\begin{array}{l}\text { Multivariate HR (95\% } \\
\text { Cl) }\end{array}$ & $P$ value & $\begin{array}{l}\text { Multivariate HR } \\
(95 \% \mathrm{Cl})\end{array}$ & $P$ value \\
\hline$\beta 2 M G(m g / L)$ & $1.054(1.008,1.102)$ & 0.022 & $\begin{array}{l}1.439(1.047 \\
1.979)\end{array}$ & 0.025 \\
\hline Age (years) & $1.026(1.004,1.048)$ & 0.018 & $\begin{array}{l}0.965(0.932 \\
0.999)\end{array}$ & 0.043 \\
\hline CCl updated & $1.132(0.980,1.308)$ & 0.093 & $\begin{array}{l}1.599(1.139 \\
2.245)\end{array}$ & 0.007 \\
\hline $\begin{array}{l}\text { Disorders of consciousness, } n \\
(\%)\end{array}$ & $0.888(0.499,1.578)$ & 0.685 & $\begin{array}{l}1.012(0.196 \\
5.231)\end{array}$ & 0.989 \\
\hline Septic shock, n (\%) & $1.104(0.616,1.980)$ & 0.740 & $\begin{array}{l}0.670(0.237 \\
1.897)\end{array}$ & 0.451 \\
\hline Albumin $(\mathrm{g} / \mathrm{L})$ & $0.966(0.923,1.012)$ & 0.144 & $\begin{array}{l}0.956(0.859 \\
1.064)\end{array}$ & 0.407 \\
\hline cTnl (ng/mL) & $0.989(0.860,1.138)$ & 0.880 & $\begin{array}{l}1.302(0.640 \\
2.651)\end{array}$ & 0.455 \\
\hline PCT (ng/mL) & $0.999(0.977,1.021)$ & 0.914 & $\begin{array}{l}0.964(0.915 \\
1.016)\end{array}$ & 0.176 \\
\hline PT (s) & $1.003(0.984,1.021)$ & 0.784 & $\begin{array}{l}1.327(1.055 \\
1.669)\end{array}$ & 0.016 \\
\hline Lactic acid (mmol/L) & $1.025(0.975,1.077)$ & 0.328 & $\begin{array}{l}1.252(0.869 \\
1.803)\end{array}$ & 0.225 \\
\hline $\mathrm{PaO}_{2} / \mathrm{FiO}_{2}$ ratio & $0.996(0.992,1.001)$ & 0.086 & $\begin{array}{l}0.997(0.989 \\
1.005)\end{array}$ & 0.486 \\
\hline SOFA score & $1.059(0.969,1.157)$ & 0.205 & $\begin{array}{l}1.272(1.003 \\
1.614)\end{array}$ & 0.047 \\
\hline
\end{tabular}

A Cox proportional hazards analysis was performed. Data are the HR $(95 \% \mathrm{Cl})$. Adjusted for age, updated $\mathrm{CCl}$, disorders of consciousness, septic shock, albumin, cTnl, procalcitonin, prothrombin time, lactic acid, $\mathrm{PaO}_{2} / \mathrm{FiO}_{2}$ ratio and SOFA score. $P<0.05$ were considered statistically significant.

Abbreviations: ARDS, acute respiratory distress syndrome; $\beta 2 \mathrm{MG}, \beta 2$-microglobulin; $\mathrm{CCl}$, Charlson comorbidity index; $\mathrm{Ccr}$, creatinine clearance rate; $\mathrm{Cl}$, confidence interval; $\mathrm{CTnl}$, cardiac troponin I; $\mathrm{FiO}_{2}$, fraction of inspired oxygen; $\mathrm{HR}$, hazard ratio; $\mathrm{PaO}_{2}$, partial pressure of arterial oxygen; $\mathrm{PCT}$, procalcitonin; PT, prothrombin time; SOFA, Sequential Organ Failure Assessment. 


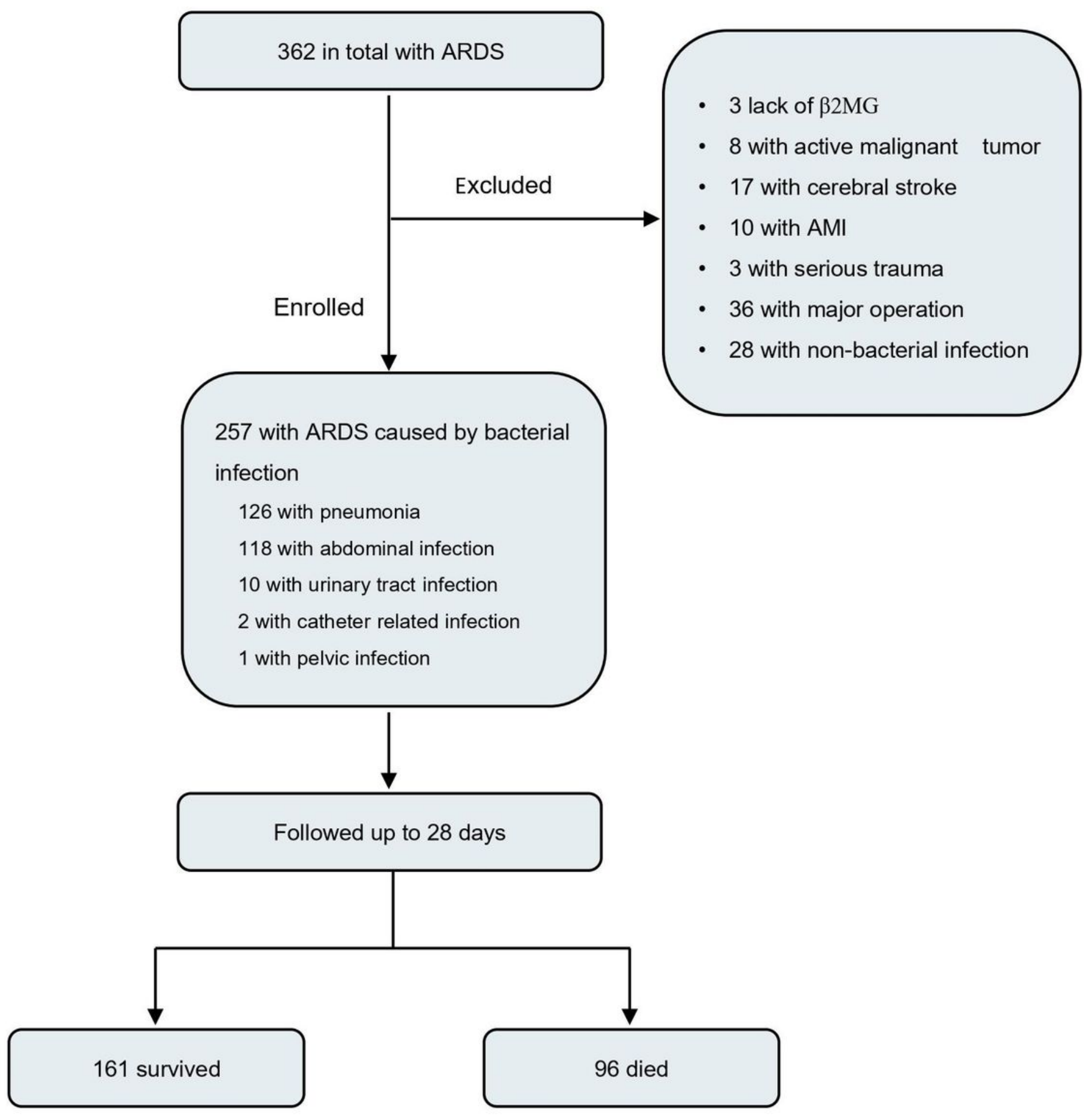

Figure 1

Flow chart of the patient enrollment and outcomes in this study.

Abbreviations: AMI, acute myocardial infarction; ARDS, acute respiratory distress syndrome; $\beta 2 \mathrm{MG}, \beta 2-$ microglobulin. 


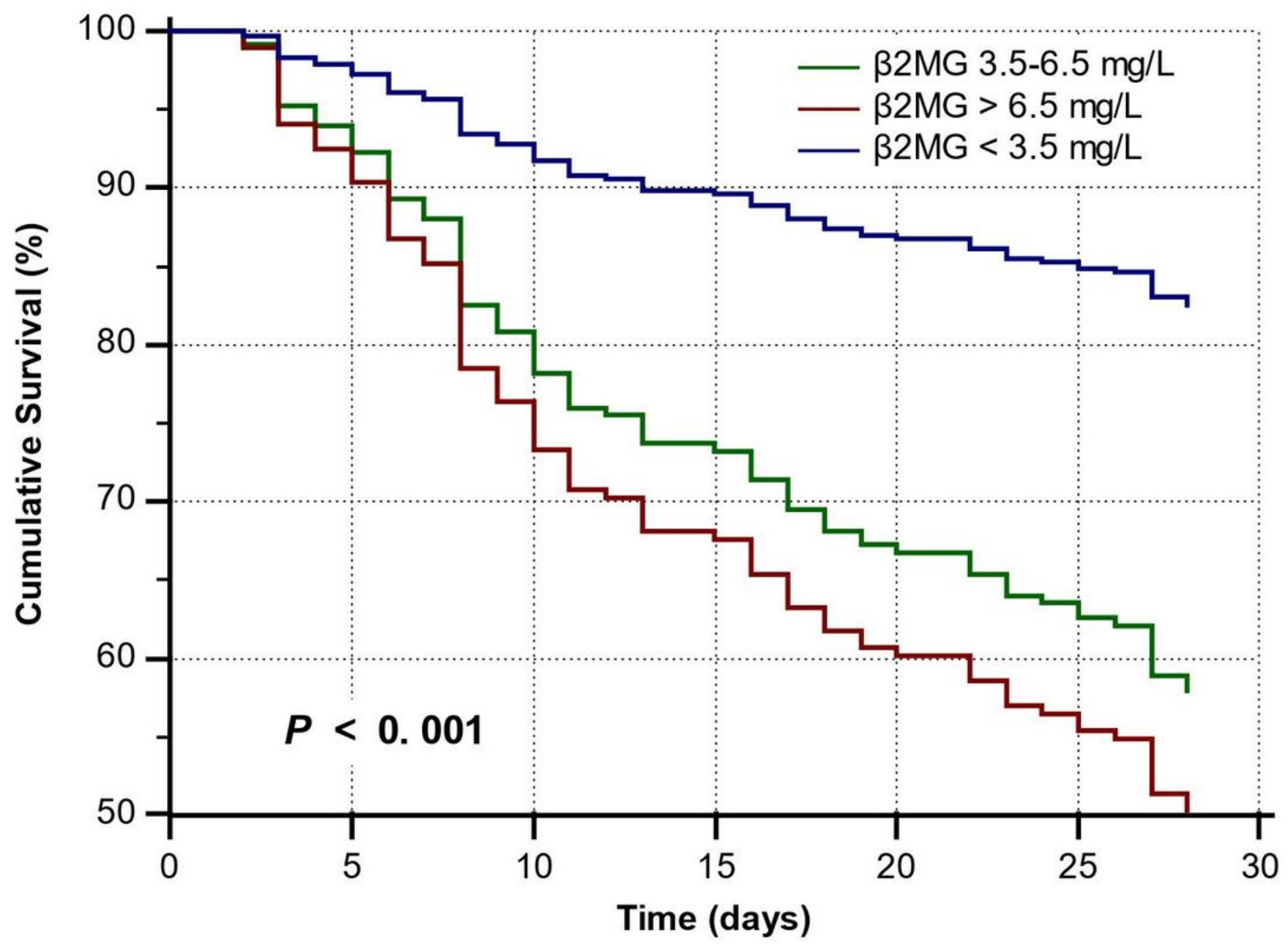

Figure 2

Survival curves of patients with ARDS stratified by $\beta 2 M G$ tertile.

Data were adjusted for age, updated $\mathrm{CCl}$, disorders of consciousness, septic shock, albumin level, cTnl level, PCT level, PT, lactic acid level, and $\mathrm{PaO}_{2} / \mathrm{FiO}_{2}$ ratio, $\mathrm{Ccr}$, AKI and SOFA score.

Abbreviations: AKI, acute kidney injury; ARDS, acute respiratory distress syndrome; $\beta 2 \mathrm{MG}, \beta 2$ microglobulin; $\mathrm{CCl}$, Charlson comorbidity index; Ccr, creatinine clearance rate; cTnl, cardiac troponin I; $\mathrm{FiO}_{2}$, fraction of inspired oxygen; $\mathrm{PaO}_{2}$, partial pressure of arterial oxygen; PCT, procalcitonin; PT, prothrombin time; SOFA, Sequential Organ Failure Assessment. 


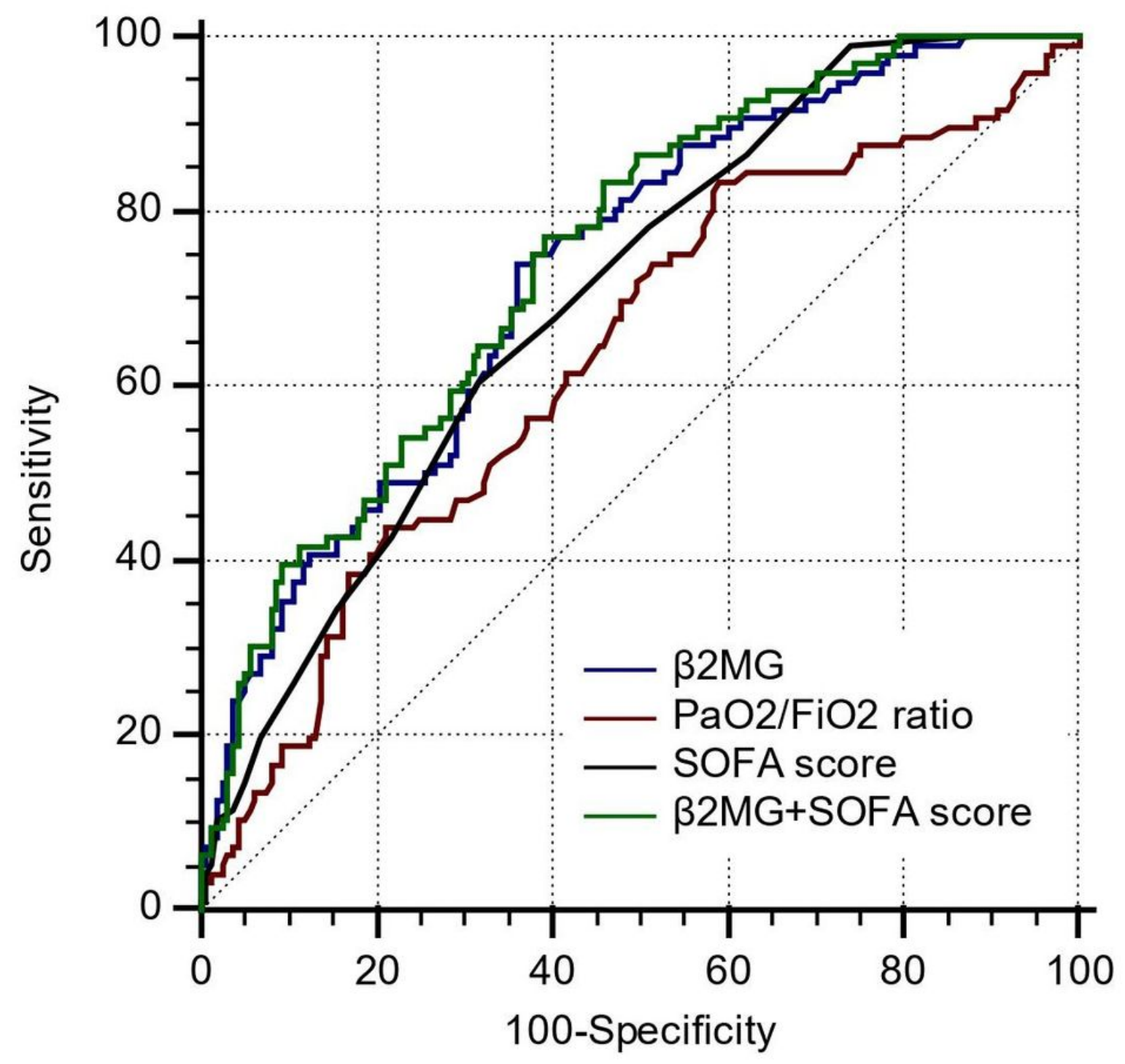

Figure 3

Prediction of 28-day mortality in patients with ARDS.

\section{Supplementary Files}

This is a list of supplementary files associated with this preprint. Click to download.

- Table.docx 